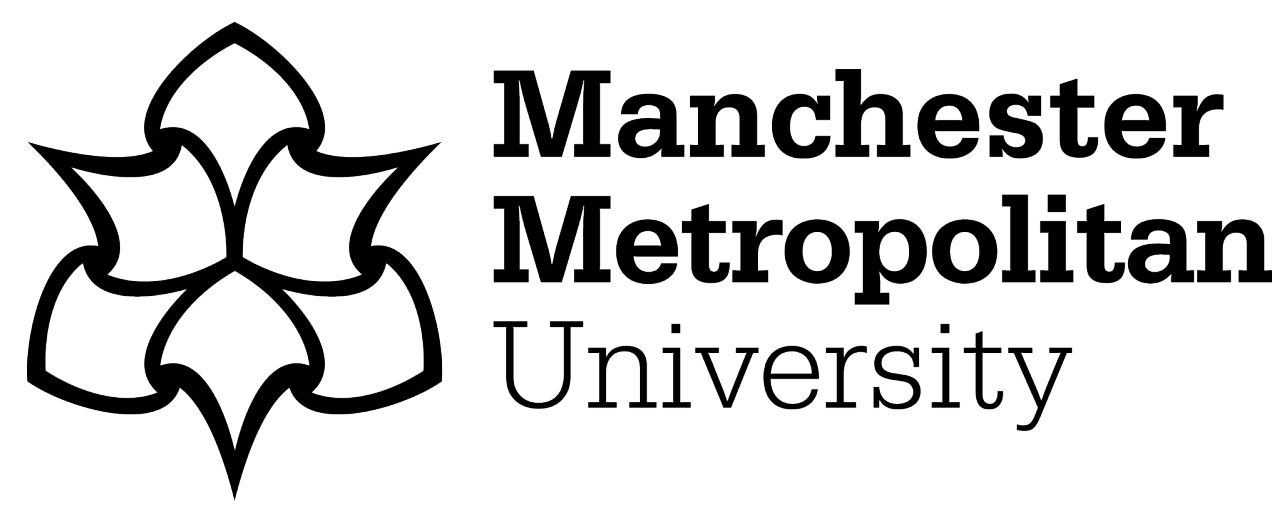

Trofimovich, Pavel, McDonough, Kim, Dao, Phung ORCID logoORCID: https://orcid.org/0000-0002-8612-5589 and Abashidze, Dato (2022) Attitudinal bias, individual differences, and second language speakers' interactional performance. Applied Linguistics Review, 13 (1). pp. 99-116. ISSN 18686303

Downloaded from: https://e-space.mmu.ac.uk/623469/

Version: Accepted Version

Publisher: Walter de Gruyter GmbH

DOI: https://doi.org/10.1515/applirev-2019-0010

Please cite the published version 
Accepted May 13, 2019 Published online June 14, 2019

Cited as: Trofimovich, P., McDonough, K., Dao, P., \& Abashidze, D. Attitudinal bias, individual differences, and second language speakers' interactional performance. Applied Linguistics Review.

\section{Attitudinal Bias, Individual Differences, and Second Language Speakers' Interactional Performance}

\section{Authors:}

1. Pavel Trofimovich, Department of Education (S FG 5.150), Concordia University, Montreal, Quebec H3G 1M8, Canada, E-mail: Pavel.Trofimovich@concordia.ca

2. Kim McDonough, Department of Education (S FG 5.150), Concordia University, Montreal, Quebec H3G 1M8, Canada

3. Phung Dao, Languages, Information and Communications, Manchester Metropolitan University, Q3 Geoffrey Manton, All Saints Campus, Manchester M15 6BH, UK

4. Dato Abashidze, Department of Education (S FG 5.150), Concordia University, Montreal, Quebec, H3G 1M8, Canada

This study examined whether an interlocutor's attitudinal bias affects second language (L2) speakers' recall of narratives and their responses to corrective feedback (recasts) and whether the role of attitudinal bias depends on individual differences in speakers' background and personality characteristics. After receiving a positive or negative attitudinal bias orientation, 70 L2 English speakers completed tasks with an interlocutor who provided recasts in response to language errors. Speakers also completed questionnaires targeting individual differences in their motivation and acculturation to the home and target cultures. There were no general effects for positive or negative attitudinal bias on speakers' recall of personal narratives or responses to feedback. However, under negative bias, motivation scores were associated with speakers' 
accurate reformulation of errors. Under positive bias, there was an association between accurate narrative recall and greater psychological adaptation and motivation. Results imply that attitudinal bias plays a subtle role in L2 speakers' interactional performance. 


\section{Introduction}

In response to calls for second language (L2) acquisition researchers to embrace a social turn in L2 research and to bridge the social-cognitive divide (e.g., Hulstijn et al., 2014), recent interaction research has expanded from a largely cognitive orientation to an approach that considers the role of social variables. For example, social factors such as interlocutor grouping (e.g., pairs or small groups), interpersonal relationships between learners and their teachers, and learners' positioning towards a task have all been shown to influence learners' engagement in various interactional processes_-providing and receiving feedback, producing language, or attending to corrections (Choi \& Iwashita, 2016; Philp \& Duchesne, 2008; Philp \& Mackey, 2010; Toohey, 2000). This study's goal was to extend this research by examining how a previously underexplored social variable — an interlocutor's language attitudes — might interact with L2 speakers' individual differences in motivation and acculturation in affecting speakers' performance, operationalized as recall of spoken narratives and responses to corrective feedback.

Among various social factors, which include language power and status, group boundary, identity, community practices, and institutional forces (e.g., Saville-Troike, 2017), the role of interlocutors' attitudes has been unexplored in relation to L2 interaction. However, people readily use language, and especially speech, to make inferences about fellow speakers' social groups and attribute various judgments to them (Giles \& Watson, 2013). While not all language attitudes are negative, such that speakers of British English are often perceived as being more courteous and educated than speakers of other English varieties (Dalton-Puffer et al., 1997), many attitudes reflect negative, stereotypical biases. For instance, speakers of standard language varieties frequently downgrade nonstandard speakers, including L2 speakers, on such traits as intelligence, competence, education, and achievement (Fuertes, Gottdiener, Martin, Gilbert, \& 
Giles, 2012). Such judgments, which reflect listeners' negative dispositions toward L2 speakers (Gluszek \& Dovidio, 2010a) or listeners' subjective difficulty in processing L2 speech (Dragojevic \& Giles, 2016), often lead to L2 speakers feeling stigmatized and being discriminated against (Gluszek \& Dovidio, 2010b).

In light of the important role of language in eliciting various forms of stereotypes and biases, it is surprising that little research has thus far investigated the impact of attitudinal biases on L2 speakers' interactional performance. There is mounting evidence suggesting that various forms of attitudes and biases influence language users in nontrivial ways. For example, Niedzielski (1999) showed that it is possible to influence what listeners perceive in a speaker's speech by providing a single piece of information about the speaker, namely, whether the speaker is a resident of the United States or Canada. Listeners tended to hear specific sounds in a speaker's speech based on where they believed the speaker came from, rather than on the actual speech content. Similarly, Hu and Lindemann (2009) demonstrated that listeners evaluate the same speakers differently depending on whether they believe that the speech sample they heard belonged to an English speaker in the United States as opposed to when they were told that it belonged to an English speaker from China.

Perhaps more importantly, language attitudes can impact speakers' language performance. In a study set in an Italian-German bilingual community in Italy, Paladino et al. (2009) explored the effect of stereotype threat (i.e., a negative judgment about a social group) on Italian-dominant speakers' performance in German (their L2). These speakers underperformed on written and oral tests of German after a negative stereotypical judgment about the German language abilities of their ethnic group was voiced explicitly and even when this sentiment was only implied (see also Miller, Fox, Moser, \& Godfroid, 2018). More recently, Taylor Reid et al. 
(2018) showed that English listeners evaluating oral performance by L2 speakers significantly downgraded their ratings of these speakers when listeners heard a negative statement about these speakers' speaking ability, compared when no such statement was made. In a compelling study, Rubin (1992) showed that American undergraduate students attributed strong accent to a university lecture paired with an image of a Chinese-looking female and - most strikinglycomprehended significantly less content from this lecture, compared to the same lecture paired with an image of a Caucasian female, even though the audio was recorded in both cases by the same English speaker from Ohio (see also Rubin 2002, 2012). Hu and $\mathrm{Su}$ (2015) reported similar findings with Cantonese speakers of L2 English as participants. These findings thus imply that perceived negative attitudes can influence the comprehension of spoken narratives, and could potentially impact other interactional behaviors, such as responses to corrective feedback.

\section{The Current Study}

Therefore, to provide a greater understanding of social influences on L2 interaction, we investigated the role of an interlocutor's language attitudes in L2 speakers' performance in interaction. We focused on two measures of L2 speakers' performance-comprehension of an interlocutor's brief personal narrative and responses to corrective feedback (operationalized as recasts, which refer to an interlocutor's target reformulations of a speaker's erroneous utterances). The choice of comprehension was motivated by previous work showing consistent detriments in native-speaking listeners' comprehension of oral discourse (typically university lectures), with such detriments linked to attitudinal biases (Hu \& Su, 2015; Rubin, 2002, 2012). By targeting responses to recasts, we sought to extend the rich literature on interactional feedback (Plonsky \& Brown, 2015) to determine how an interlocutor's attitudes impact L2 speakers' responses to recasts. Apart from few exceptions, which includes Sheen's (2008) work 
showing that anxiety as a sociocognitive phenomenon can moderate the effectiveness of recasting for L2 learners (see also DeKeyser, 1993; Yoshida, 2010), prior work on corrective feedback, most of which targeted recasts, has focused on cognitive learner-internal factors, such as L2 speakers' working memory (e.g., Révész, 2012), aptitude (e.g., Yilmaz \& Granena, 2016), verbal intelligence (e.g., Havranek \& Cesnik, 2001), developmental readiness (e.g., Mackey \& Philp, 1998), attention control (e.g., Trofimovich et al. 2007), and analytic ability (e.g., DeKeyser, 1993; Trofimovich et al. 2007). Previous research has also documented various linguistic dimensions underlying the effectiveness of recasting, including the type of linguistic target, its length, and degree of salience (Mackey, Gass, \& McDonough, 2000; Philp, 2003; Carpenter, Jeon, MacGregor, \& Mackey, 2006; Loewen \& Philp, 2006; Sheen 2006; Egi, 2007). Yet presently little is known about the role of social factors, including interlocutor attitudes, in shaping L2 speakers' responses to recasts.

The effect of language attitudes on L2 speakers' comprehension of narratives and their responses to recasts was operationalized as a deliberate positive or negative bias orientation provided by the interlocutor to the L2 speaker before they engaged in interaction. Immediately before interaction, half of the L2 speakers heard a short personal opinion by the interlocutor either criticizing or praising English skills of fellow L2 speakers. The working assumption was that a subtle bias introduced at the outset of the interaction and directed at the L2 speaker would either enhance or suppress the speaker's interactive behaviors, leading to potential benefits or detriments in performance. Based on prior research on the role of attitudes in native-speaking listeners' comprehension (e.g., Rubin, 2012), we expected L2 speakers exposed to a negative attitudinal bias to show lower comprehension scores than speakers exposed to a positive bias. If overt or implied attitudinal judgments influence L2 speakers' performance on written and oral 
tests (e.g., Paladino et al., 2009) and negatively impact listener comprehension (e.g., Rubin, 1992), then a negative bias might also suppress the extent to which L2 speakers respond to interactional feedback. For instance, a negative bias might make L2 speakers' less willing to accept their interlocutors' conversational modifications as corrective feedback or might make them less interested in responding to that feedback.

Because L2 speakers' reactions to language attitudes might depend on individual differences in their background and personality characteristics, including, for example, the extent of their acculturation to the home and target cultures, their psychological adaptation, and their L2 learning motivation (e.g., Doucerain, Varnaamkhasti, Segalowitz, \& Ryder, 2015; Kang \& Rubin, 2009; MacIntyre \& Vincze, 2017), we measured these variables using questionnaires. The assumption was that these individual difference variables might moderate the extent to which L2 speakers might be affected by an interlocutor's attitudes in terms of their comprehension of an interlocutor's personal narrative and their responses to recasts. The following research questions guided this study:

1. Does an interlocutor's attitudinal bias (positive, negative) about the language skills of fellow L2 speakers affect speakers' recall of personal narratives and their responses to recasts?

2. Do L2 speakers' acculturation to the home and target cultures, their psychological adaptation, and their L2 learning motivation moderate their performance in recall of personal narratives and responses to recasts?

\section{Method}

\section{Participants}

Participants included 70 L2 English students (41 women) enrolled in degree programs at 
an English-medium university in Montreal, Canada. They reported a mean age of 25.4 years ( $S D$ $=4.7)$ and a mean residence in Canada of 3.4 years $(S D=3.3)$. Participants' L1 backgrounds included Mandarin (24), Vietnamese (13), Farsi (13), Arabic (7), French (6), Spanish, Russian, Swedish, and Ukrainian (1 each). They reported studying English previously for a mean of 10.9 years $(S D=5.3)$. In terms of standardized proficiency tests, participants who reported IELTS scores $(n=43)$ had a mean total score of $6.4(S D=.5)$, while those reporting TOEFL iBT scores $(n=17)$ had a mean score of 86.2 (SD 10.4). The two research assistants (RAs) who carried out all interactive activities with participants in English (henceforth, RA interlocutors) were a male and a female French-English bilinguals both in their late 20s. Both RA interlocutors were enrolled in an MA program in applied linguistics and had extensive L2 English teaching experience.

\section{Materials}

The materials consisted of personal narratives, two interactive tasks, three questionnaires, and a debrief worksheet. The personal narratives were written by the two RA interlocutors. They audio-recorded themselves narrating an event from their own lives, after which the recordings were transcribed. The researchers then edited the transcripts so that the stories were comparable in length and propositional content. The original narratives contained 15-16 separate propositions (Stein \& Glenn, 1979), typically expressed in a single clause or two brief clauses (e.g., "so I was living and working in Whistler in British Colombia one summer," "we tried to find our way to the nearest cab but could not find any"). The RAs then used their personal narrative script when narrating their stories to the participants.

The two interactive activities were an interview task and a discussion task based on TED talks. The interview task was based on 12 cards that listed the following topics: travel and 
adventure; love, dating, and marriage; dreams and goals; social media; science and technology; music and entertainment; jobs and occupations; the environment; inspirational people; moving to a different country; restaurants and fine cuisine; and stress and relaxation. The TED talk task was a discussion about one of two videos (green building or web tracking) selected by the participant. The discussion consisted of warm-up questions, summary of the lecture, and an exchange of opinions about the topic and themes raised by the presenter.

Three questionnaires (Appendix A) were administered to the participants to determine (a) their acculturation orientation towards their home and Canadian culture, (b) their psychological adaptation (both drawn from Demes \& Geeraert, 2014), and (c) their L2 learning motivation (items from Dörnyei, 2010). The culture questionnaire contained eight Likert-scale items $(1=$ strongly disagree, 7 = strongly agree) which elicited participants' attitudes toward their home culture and Canadian culture, such as the value of cultural friendships, taking part in traditions, preserving cultural traits, and participating in cultural activities (four items per culture). The psychological adaptation questionnaire contained eight Likert-scale items $(1=$ never, $7=$ always $)$ that asked how often in the past two weeks participants had experienced several positive feelings (e.g., happy, excited) and negative emotions (e.g., frustrated, sad, nervous) about living in Canada. The L2 motivation questionnaire consisted of 15 Likert-scale items $(1=$ strongly disagree, 6 = strongly agree) distributed across five domains: promotion orientation, prevention orientation, attitude, and interest, and ethnocentrism. The internal response consistency (Cronbach's $\alpha$ ) was .80 for orientation toward home culture, .76 for orientation toward Canadian culture, .76 for psychological adaptation, and .69 for L2 motivation.

\section{Procedure}

Participants carried out the research activities during individually scheduled sessions (120 
minutes), which also included the use of eye-tracking to monitor eye gaze behaviors (not reported here), with two researchers (RA interlocutor and RA assistant). Participants were randomly assigned to the two RA interlocutors. After completing a consent form (5 minutes), the participants underwent a brief calibration for the eye-tracking equipment (15 minutes) with the RA assistant who then left the room. At this time, the RA interlocutor entered the room while simulating a phone conversation with a customer service agent at a telecommunications company. Upon ending the call, the RA interlocutor delivered the critical attitudinal manipulation by providing a biasing orientation to each participant. The RA either commented positively about how the customer service agent was a recent immigrant to Canada with excellent English skills (positive bias orientation) or made negative remarks about the agent's English skills (negative bias orientation). Although the biasing orientation was scripted (Appendix B), it was delivered naturally in the form of a personal commentary as part of the RA's transition from talking on the phone and greeting the participant to starting the session. Participants were randomly assigned to the positive or negative bias condition.

After delivering the biasing script, the RA interlocutor informed the participant that the first task consisted of sharing personal stories, then narrated his or her narrative, and then requested a similar narrative from the participant (20 minutes). Participants were not instructed to attend to any aspect of the RA's or their own narrative, nor were they informed that their memory for the RA's narrative would be tested subsequently. Next, the participant and the RA interlocutor carried out the interview task (15 minutes) and the TED talk discussion (25 minutes), during which the RA provided recasts when the participant produced language errors. The types of errors to be recast or the number of recasts to provide were not decided a priori. Instead, the interlocutor was instructed to provide recasts whenever he or she felt it was 
appropriate. Then, the participant went to an adjoining room where the RA assistant administered the questionnaires ( 25 minutes) and debriefed each participant about his or her perceptions of the tasks and the RA interlocutor using a brief worksheet containing several 100millimeter rating scales and open-ended questions (10 minutes). Finally, the participant was asked to retell the RA interlocutor's personal narrative, recalling as much detail as possible (5 minutes). All interactions were audio-recorded using a Sony digital recorder.

\section{Data Coding}

As an initial step in data coding, we examined if participants assigned to the two bias conditions differed in their reactions to the testing situation by analyzing their perceptions of the tasks, equipment, and the interlocutor during the debrief interview. Comparisons of the ratings from the debrief worksheet confirmed that participants did not differ in their reactions to the interlocutor, finding the interlocutor helpful $\left(M_{\text {positive }}=93.4, M_{\text {negative }}=92.5\right)$, competent $\left(M_{\text {positive }}\right.$ $\left.=93.1, M_{\text {negative }}=92.0\right)$, and friendly $\left(M_{\text {positive }}=97.8, M_{\text {negative }}=94.1\right)$. No participants in either condition reported difficulty completing tasks. Most importantly, participants appeared to be similarly unaware of the attitudinal bias across both conditions.

The audio-recordings were transcribed and verified by additional RAs. The interaction data were coded for recasts, which were operationalized as more accurate reformulations of participants' erroneous forms. The type of error targeted in each recast was classified as being about grammar, lexis, phonology, or multiple errors involving different forms. Participants' responses to recasts were coded as "target reformulation" if they produced the form recast by the RA or "no reformulation" if they simply acknowledged the recast (e.g., yeah, uh huh, right) or continued the conversation. To determine the rate of target reformulation, a proportion score was computed by summing the number of target responses and dividing it by the total number of 
recasts received by each participant. An independent rater coded a subset of the data (20\%) with interrater reliability obtained through Pearson correlations for the number of recasts (.95) and Cohen's kappa for error type (.82) and participant responses (.87).

Although the RA interlocutors' personal narratives were prepared in advance so that they could produce comparable stories, there was variation in their delivery. Therefore, the RA interlocutors' personal stories were analyzed based on how they were narrated to each participant. The narrative and the participant's recall of that narrative were coded for the number of propositions, defined by Stein and Glenn (1979) as a predicate (e.g., verb) and one or more arguments that relate back to the predicate (e.g., subject). Although Stein and Glenn's scheme allows for coding of specific proposition types, such as setting (e.g., "so the scariest thing that happened to me is when I was in China") or direct consequence (e.g., "that's when we started running away"), all propositions were treated similarly, regardless of their type. In addition, propositions in the participants' recalls were classified along two broad categories: as correctly recalled if the main idea of the proposition had been roughly present in the original RA narrative (e.g., "so I was living and working in Whistler in British Colombia one summer" recalled as "She was near Vancouver") or as false recall if the RA had not mentioned the idea (e.g., "she wanted to keep her distance from the bears" when this was not discussed in the original story) or if the original idea had been recalled incorrectly or altered during recall (e.g., "they went back to the airport" whereas the story characters never left the airport). To measure the accuracy of correct versus false recall, proportion scores were derived for each participant as ratios of the total number of correct and false recall propositions over the total number of propositions in the RA's narrative. A subset of the data (20\%) was coded by an independent rater, and the Pearson correlation coefficients were .88 for RA propositions, .81 for number of correctly recalled 
propositions, and .88 for falsely recalled propositions.

\section{Results}

The first research question asked whether the interlocutor's attitudinal bias (positive, negative) about the language skills of fellow L2 speakers affected L2 speakers' listening comprehension (measured through recall) and their responses to conversational recasts. For narrative recall, the negative bias condition elicited slightly higher rates of correct recall (.35) than the positive bias condition (.31). In addition, the negative bias condition elicited slightly fewer false recalls (.06) than positive bias condition (.07). However, as shown in Table 1, the difference between the two bias conditions was not significant for either correct or false recall. In terms of responses to recasts, $\mathrm{L} 2$ speakers received a total of 1,318 recasts $(M=13.8, S D=10.1)$ after grammatical (69\%), lexical (23\%), phonological (7\%), and multiple errors (1\%). They responded to the majority of those recasts without reformulating their erroneous forms ( $70 \%$ or 925/1,318). Table 1 shows the rate of L2 speakers' target reformulations in response to recasts, separately in the positive and negative bias conditions. This rate (about 30\%) did not appear to depend on bias orientation.

Table 1. Linguistic Performance by Social Bias Orientation

\begin{tabular}{|c|c|c|c|c|c|c|c|}
\hline \multirow[b]{2}{*}{ Measure } & \multicolumn{2}{|c|}{ Positive bias } & \multicolumn{2}{|c|}{ Negative bias } & \multicolumn{3}{|c|}{ Comparison } \\
\hline & $M$ & $S D$ & $M$ & $S D$ & $t(68)$ & $p$ & $d$ \\
\hline Correct recall & .31 & .14 & .35 & .14 & 1.42 & .16 & 0.29 \\
\hline False recall & .07 & .06 & .06 & .05 & 0.30 & .76 & 0.18 \\
\hline Target reformulation & .28 & .23 & .31 & .22 & 0.55 & .58 & 0.13 \\
\hline
\end{tabular}

The second research question asked whether there was a relationship between L2 
speakers' linguistic performance - in terms of their recall of the interlocutor's personal narrative and responses to recasts - and several individual difference variables (acculturation orientation towards home and Canadian culture, psychological adaptation, L2 learning motivation). We hypothesized that these variables might vary in their associations with measures of linguistic performance depending on the attitudinal bias (positive, negative). For this analysis, Pearson correlations between the measures of L2 speakers' linguistic performance and their questionnaire scores (summed as responses to all relevant questions and summarized in Table 2) were computed separately in each bias condition.

Table 2. Summary of Individual Difference Variables

\begin{tabular}{|c|c|c|c|c|c|c|c|}
\hline \multirow[b]{2}{*}{ Measure } & \multicolumn{2}{|c|}{ Positive bias } & \multicolumn{2}{|c|}{ Negative bias } & \multicolumn{3}{|c|}{ Comparison } \\
\hline & $M$ & $S D$ & $M$ & $S D$ & $t(68)$ & $p$ & $d$ \\
\hline Home culture & 19.17 & 5.06 & 17.27 & 6.17 & 1.39 & .17 & 0.34 \\
\hline Canadian culture & 23.47 & 3.37 & 21.88 & 4.32 & 1.69 & .10 & 0.41 \\
\hline Adaptation & 38.82 & 8.48 & 39.97 & 7.89 & 0.58 & .56 & 0.14 \\
\hline Motivation & 74.63 & 6.18 & 71.31 & 7.85 & 1.96 & .06 & 0.48 \\
\hline
\end{tabular}

As shown in Table 3, the proportion of target reformulations in response to recasts was significantly associated only with speakers' motivation scores $(r=.34, p=.05)$, and only in the negative bias condition. In contrast, the rate of correctly recalled propositions from the RA's personal narrative was significantly associated with L2 speakers' psychological adaptation scores $(r=.36, p=.035)$ and their motivation scores $(r=.35, p=.04)$, but only in the positive bias condition. These correlations approached the benchmark (.40) for medium-strength relationships (Plonsky \& Oswald, 2014). 
Table 3. Pearson Correlations Between Participants' Questionnaire Scores and Their Responses to Recasts (targetlike Reformulation) and Personal Narrative Recall by Social Bias Orientation

\begin{tabular}{|c|c|c|c|c|c|c|}
\hline \multirow[b]{3}{*}{ Variable } & \multicolumn{3}{|c|}{ Positive bias $(n=35)$} & \multicolumn{3}{|c|}{ Negative bias $(n=35)$} \\
\hline & \multirow{2}{*}{$\begin{array}{l}\text { Targetlike } \\
\text { reformulation }\end{array}$} & \multicolumn{2}{|c|}{ Recall } & \multirow{2}{*}{$\begin{array}{l}\text { Targetlike } \\
\text { reformulation }\end{array}$} & \multicolumn{2}{|c|}{ Recall } \\
\hline & & Correct & False & & Correct & False \\
\hline Home culture & 0.25 & 0.16 & 0.08 & 0.08 & 0.22 & 0.06 \\
\hline Canadian culture & 0.24 & 0.16 & -0.16 & 0.03 & -0.13 & -0.02 \\
\hline Adaptation & -0.29 & $0.36^{*}$ & 0.07 & -0.21 & -0.07 & 0.01 \\
\hline Motivation & 0.22 & $0.35^{*}$ & -0.10 & $0.34 *$ & -0.10 & 0.09 \\
\hline
\end{tabular}

\section{Discussion}

Motivated by prior work investigating social influences on language performance (Hu \& Su, 2015; Paladino et al., 2009; Rubin, 1992), this study explored whether an interlocutor's language attitudes influenced L2 speakers' performance in interaction. We found no general effects for positive or negative attitudinal bias on L2 speakers' memory for a personal narrative or their responses to recasts. However, several individual difference variables showed associations with measures of L2 speakers' performance as a function of attitudinal bias. Speakers with higher L2 learning motivation scores showed greater rates of target reformulation, but only under negative bias. Speakers with greater psychological adaptation and L2 learning motivation scores were more likely to accurately recall their interlocutor's personal narrative, but only under positive bias.

Contrary to predictions based on social psychological research with native speakers (Kang \& Rubin, 2009; Rubin, 1992) and with bilinguals and L2 learners (Hu \& Su, 2015; Miller et al., 2018; Paladino et al., 2009), no general effect of attitudinal bias was detected in this study 
for L2 speakers' comprehension of an interlocutor's personal narrative or for speakers' responses to recasts. In terms of listening comprehension, the most consistent evidence for attitudinal effects has thus far come from research with native speakers, whose comprehension is measured through a cloze test administered immediately after listening tasks (Rubin, 2002, 2012). It may be that completing transcripts of listening materials - for example, a 410-word transcript of a lecture with every seventh word gapped (Kang \& Rubin, 2009) - might be a more sensitive comprehension measure than recall in order to capture the impact of attitudes. A more plausible explanation, however, might be related to the delay between speakers' exposure to a biasing opinion and a test of their comprehension. In fact, 15 minutes might represent a boundary condition for revealing sustained effects of affective or emotional factors on cognitive processing (Miller et al., 2018; Pessoa, 2009), so expecting that attitudinal bias would strongly impact L2 speakers' recall about 1.5 hours after being exposed to a biased opinion might have been unrealistic.

Whereas the impact of attitudinal bias on listening comprehension could have been subject to time-sensitive affective responses or general memory decays, the time interval between the attitudinal bias delivered to L2 speakers and their performance in the interactive tasks was considerably shorter (about 20-40 minutes). We had reasoned that positive or negative attitudes might alter L2 speakers' interaction behaviors, for instance, making them less willing to accept their interlocutors' conversational modifications as error correction or less likely to respond to recasts. However, there was no evidence in our specific measure of L2 speakers' responses to recasts or in our post-hoc impressionistic video observation of speaker interaction that attitudinal bias produced a consistent general effect on speakers' conversational behavior. Besides time delay, existing literature offers at least two plausible explanations for the 
absence of strong, general effects of attitudinal bias on L2 speakers' linguistic performance in this study. Miller et al. (2018) reported that paired-associate learning of new L2 words was disrupted for participants after viewing negative videos (clips from horror films), compared to a neutral condition (clips of scenery), but only in terms of participants' access to the semantic knowledge in their native language. They reasoned that a negative bias may have disrupted the process of integration of new information with existing knowledge structures. If attitudes mostly impact the creation and integration of new lexical form-meaning mappings (Miller et al., 2018), then it is unsurprising that there was no pronounced effects of attitudinal bias on the deployment of existing linguistic knowledge by these advanced L2 speakers.

Another reason for the lack of strong, general effects of attitudinal bias in this study may be related to the particular interlocutors employed here. The two interlocutors, who were native speakers of French and highly proficient in English, were essentially L2 speakers themselves, and their L2 speaker status was detectable to a discerning listener through a subtle French accent in English. Prior research on cross-cultural communication has revealed that homophily, which refers to people's perceptions of similarity between themselves and a knowledge source, may moderate the strength of attitudinal judgments (McCroskey, Richmond, \& Daly, 1975). For instance, the impact of attitudes is minimized when people perceive similarity in values, background, appearance, or attitudes between themselves and the people they are evaluating (e.g., Elliot, 1979; Watts, 1999). It might be the case that the impact of positively and negatively biased opinions expressed by the interlocutors may have been minimized because L2 speakers perceived some affinity with the interlocutor as a fellow L2 user. It would thus be important to compare potential effects of attitudinal judgments on L2 speaker interactional performance when attitudes are expressed by different kinds of interlocutors such as native speakers, advanced L2 
users, bilinguals, or language speakers from specific political, ethnic, or religious backgrounds.

Of course, one straightforward interpretation of the current findings is that the bias expressed by the interlocutor was too subtle or unclear to produce any impact at all. Yet treating attitudinal effects in this dataset as null or nonexistent is premature. This is because several of L2 speakers' personality and social variables were dissociated in their relationships with performance measures as a function of attitudinal bias (Table 3). Speakers' L2 learning motivation scores were correlated with target reformulations under negative bias but with correct recall of narratives under positive bias, and speakers' psychological adaptation scores were tied to recall of narratives but only under positive bias. These associations cannot be readily explained by L2 speakers' idiosyncratic reactions to the particular interlocutor with whom they communicated, because speakers were randomly assigned to each of the two interlocutors and because speakers did not differ in their debrief comments and ratings of the interlocutors (e.g., as helpful, competent, friendly) in the two bias conditions.

The obtained link between L2 learning motivation scores and measures of language performance aligns well with the findings of Paladino et al. (2009) who found that the speakers for whom it was important to master the L2 were particularly vulnerable to the effect of attitudinal, stereotypical judgments about the linguistic ability of their ethnic group. The current results refine this link between motivation and attitudes by suggesting that motivation might feed into different aspects of L2 performance depending on the affective or attitudinal valence of a given context of language use. This link can be understood within research investigating how people's linguistic and non-linguistic performance is affected by mood induction, which refers to manipulation of people's affective states through exposure to happy versus sad music or videos. For instance, participants who have been put into a negative mood tend to focus more on details, 
while those whose mood has been positively altered engage in more global, abstract processing (Beukeboom \& Semin, 2006; Vissers et al., 2010). Mood induction also influences the extent of attentional resources allocated by participants to semantic and visuospatial tasks, with negative moods linked to a more focused while positive moods associated with a broader, more distributed scope of attention (Rowe, Hirsh, \& Anderson, 2007). Most crucially, mood induction also appears to impact speaker behavior in interaction, with negative moods associated with a speaking style that is more sensitive to the needs of the listener and positive moods tied to egocentric interactive behaviors leading to more ambiguity in communication (Kempe, Rookes, \& Swarbrigg, 2013).

The relationship between L2 speakers' motivation and their responses to recasts under negative social bias appears to dovetail nicely with previous work in the corrective feedback literature. For instance, DeKeyser (1993) and Sheen (2008) showed that corrective feedback, including recasting, was effective for low-anxiety L2 learners (i.e., those who ostensibly might also show enhanced motivation), and Havranek and Cesnik (2001) reported corrective feedback being particularly beneficial for L2 learners with low degree of irritation, high enjoyment and motivation, and low sense of embarrassment of error correction. Assuming that a negative social bias (in line with the mood induction literature) can induce more focused attention to input and heightened sensitivity to the interlocutor (Kempe et al., 2013; Rowe et al., 2007), then already motivated learners - defined here through a composite measure across such domains as promotion orientation, prevention orientation, attitude, and interest - might experience enhanced sensitivity to language forms under negative bias, particularly when such sensitivity is required to perceive the corrective function of recasts. And because sensitivity to (erroneous) language forms was likely irrelevant to L2 speakers' recall of personal narratives, it was the positive 
affective/attitudinal mood states (likely induced through positive social bias) that contributed to L2 speakers' greater recall of personal narratives. Put differently, a positive social bas likely served as an added catalyst for motivated L2 speakers to engage in greater processing, storage, and retrieval of meaning from spoken input - in line with the argument proposed by Miller et al. (2018) — namely, through enhancing the process of storage and integration of new information.

Finally, the link between L2 speakers' psychological adaptation scores-defined here as speakers experiencing positive (e.g., happy, excited) over negative (e.g., frustrated, sad, lonely) emotions - and their recall of personal narratives adds to the growing body of work showing the importance of emotions, especially positive ones, in L2 learning and use (MacIntyre, Gregersen, \& Mercer, 2016). Ostensibly, a positive attitudinal bias may have been particularly fitting for those L2 speakers who were well adjusted emotionally to life in Canada, contributing to their recall of spoken narratives. This finding would be consistent with research reporting links between children's social adaptation and their linguistic development (e.g., Lum, Powell, Timms, \& Snow, 2015), between immigrants' social adaptation and their L2 proficiency (e.g., Vedder \& Virta, 2005), and between L2 learners' sociocultural adaptation and their L2 performance (e.g., Sánchez-Hernández, 2018; see Dewaele, 2016, for review). Nevertheless, these associations between speakers' personality and social variables and their linguistic performance in interaction must be explored further to establish clear patterns for how L2 speakers' acculturation to home and host cultures, their motivation, and psychological adaptation relate to L2 performance (e.g., Doucerain et al., 2015).

\section{Conclusion}

The current study exemplifies an initial investigation into the role of attitudinal biases in shaping L2 speakers' performance in interaction, motivated by calls to examine the 
interdependence between affective and cognitive processes in interaction-driven learning (Swain, 2013). The findings, which must be treated as preliminary until confirmed in future work, suggest that attitudinal biases might have subtle effects on L2 speakers' linguistic performance in communication, interacting with individual differences in speakers' personality and social variables. Taken together, these findings encourage further research linking social and cognitive domains of L2 learning and use, with a particular focus on interaction-driven L2 learning.

\section{References}

Beukeboom, C. J., \& Semin, G. R. (2006). How mood turns on language. Journal of Experimental Social Psychology, 42, 553-566.

Carpenter, H., Jeon, K. S., MacGregor, D., \& Mackey, A. (2006). Learners' interpretation of recasts. Studies in Second Language Acquisition, 28, 209-236.

Choi, H., \& Iwashita, N. (2016). Interactional behaviours of low-proficiency learners in small group work. In M. Sato \& S. Ballinger (Eds.), Peer interaction and second language learning: Pedagogical potential and research agenda (pp. 113-134) Amsterdam: John Benjamins.

Dalton-Puffer, C., Kaltenboeck, G., \& Smit, U. (1997). Learner attitudes and L2 pronunciation in Austria. World Englishes, 16, 115-128.

DeKeyser, R. (1993). The effect of error correction on L2 grammar knowledge and oral proficiency. The Modern Language Journal, 77, 501-514.

Demes, K. A., \& Geeraert, N. (2014). Measures matter: scales for adaptation, cultural distance and acculturation orientation revisited. Journal of Cross-Cultural Psychology, 45, 82100.

Dewaele, J.-M. (2016). Multi-competence and personality. In Li Wei \& V. Cook (Eds.), The 
Cambridge handbook of linguistic multi-competence (pp. 403-419). Cambridge, UK: Cambridge University Press.

Dörnyei, Z. (2010). Questionnaires in second language research: Construction, administration, and processing (2nd ed.). New York: Routledge.

Doucerain, M. M., Varnaamkhaasti, R. S., Segalowitz, N., \& Ryder, A. G. (2015). Second language social networks and communication-related acculturative stress: The role of interconnectedness. Frontiers in Psychology, 6, 1111.

Dragojevic, M., \& Giles, H. (2016). I don't like you because you're hard to understand: The role of processing fluency in the language attitudes process. Human Communication Research, 42, 396-420.

Egi, T. (2007). Interpreting recasts as linguistic evidence: The roles of linguistic target, length, and degree of change. Studies in Second Language Acquisition, 29, 511-537.

Elliot, S. (1979). Perceived homophily as a predictor of classroom learning. In D. Nimmo (Ed.), Human Communication Yearbook 3 (pp. 585-602). New Brunswick, NJ: Transaction Books.

Fuertes, J. N., Gottdiener, W. H., Martin, H., Gilbert, T. C., \& Giles, H. (2012). A meta-analysis of the effects of speakers' accents on interpersonal evaluations. European Journal of Social Psychology, 42, 120-133.

Giles, H., \& Watson, B. (Eds.) (2013). The social meanings of accents and dialects: An international perspective. New York: Peter Lang.

Gluszek, A., \& Dovidio, J. F. (2010a). Speaking with a nonnative accent: perceptions of bias, communication difficulties, and belonging in the United States. Journal of Language and Social Psychology, 29, 224-234. 
Gluszek, A., \& Dovidio, J. F. (2010b). The way they speak: a social psychological perspective on the stigma of non-native accents in communication. Personality and Social Psychology Review, 14, 214-237.

Havranek, G., \& Cesnik, H. (2001). Factors affecting the success of corrective feedback. In S. H. Foster-Cohen \& A. Nizegorodcew (Eds.), EUROSLA Yearbook (pp. 99-122). Amsterdam: John Benjamins.

Hu, G., \& Lindemann, S. (2009). Stereotypes of Cantonese English, apparent native/non-native status, and their effect on non-native English speakers' perception. Journal of Multilingual and Multicultural Development, 30, 253-269.

Hu, G., \& Su, J. (2015). The effect of native/non-native information on non-native listeners' comprehension. Language Awareness, 24, 273-281.

Hulstijn, J., Young, R., Ortega, L., Bigelow, M., DeKeyser, R., Ellis, N.,... Talmy, S. (2014). Bridging the gap: Cognitive and social approaches to research in second language learning and teaching. Studies in Second Language Acquisition, 36, 361-421.

Kang, O., \& Rubin, D. L. (2009). Reverse linguistic stereotyping: measuring the effect of listener expectations on speech evaluation. Journal of Language and Social Psychology, 28, $441-456$.

Kempe, V., Rookes, M., Swarbrigg, L. (2013). Speaker emotion can affect ambiguity production. Language and Cognitive Processes, 28, 1579-1590.

Loewen, S., \& Philp, J. (2006). Recasts in the adult English L2 classroom: Characteristics, explicitness, and effectiveness. The Modern Language Journal, 90, 536-556.

Lum, J. A. G., Powell, M., Timms, L., \& Snow, P. (2015). A meta-analysis of cross sectional studies investigating language in maltreated children. Journal of Speech, Language, and 
Hearing Research, 58, 961-976.

MacIntyre, P. D., \& Vincze, L. (2017). Positive and negative emotions underlie motivation for L2 learning. Studies in Second Language Learning and Teaching, 7, 61-88.

MacIntyre, P. D., Gregersen, T., \& Mercer, S. (Eds.) (2016). Positive psychology in SLA. Bristol, UK: Multilingual Matters.

Mackey, A., \& Philp, J. (1998). Conversational interaction and second language development: Recasts, responses, and red herrings? The Modern Language Journal, 82, 338-356.

Mackey, A., Gass, S., \& McDonough, K. (2000). How do learners perceive interactional feedback? Studies in Second Language Acquisition, 22, 471-497.

McCroskey, J. C., Richmond, V. P., \& Daly, J. A. (1975). The development of a measure of perceived homophily in interpersonal communication. Human Communication Research, $1,323-332$.

Miller, Z. F., Fox, J. K., Moser, J. S., \& Godfroid, A. (2018). Playing with fire: Effects of negative mood induction and working memory on vocabulary acquisition. Cognition and Emotion, 32, 1105-1113.

Niedzielski, N. (1999). The effect of social information on the perception of sociolinguistic variables. Journal of Language and Social Psychology, 18, 62-85.

Paladino, M.-P., Poddesu, L., Rauzi, M., Vaes, J., Cadinu, M., \& Forer, D. (2009). Second language competence in the Italian-speaking population of Alto Adige/Südtirol: Evidence for linguistic stereotype threat. Journal of Language and Social Psychology, $28,222-243$.

Pessoa, L. (2009). How do emotion and motivation direct executive control? Trends in Cognitive Sciences, 13, 160-166. 
Philp, J. (2003). Constraints on "noticing the gap." Studies in Second Language Acquisition, 25, 99-126.

Philp, J., \& Duchesne, S. (2008). When the gate opens: the interaction between social and linguistic goals in child second language development. In J. Philp, R. Oliver, \& A. Mackey (Eds.), Second language acquisition and the younger learners: Child's play? (pp. 83-103). Amsterdam: John Benjamins.

Philp, J., \& Mackey, A. (2010). Interaction research: what can socially informed approaches offer to cognitivists (and vice versa)? In R. Batstone (Ed.), Sociocognitive perspectives on language use and language learning (pp. 210-228). New York: Oxford University Press.

Plonsky, L., \& Brown, D. (2015). Domain definition and search techniques in meta-analyses of L2 research (Or why 18 meta-analyses of feedback have different results). Second Language Research, 31, 267-278.

Plonsky, L., \& Oswald, F. (2014). How big is “big”? Interpreting effects sizes in L2 research. Language Learning, 64, 878-912.

Révész, A. (2012). Working memory and the observed effectiveness of recasts on different L2 outcome measures. Language Learning, 62, 93-132.

Rowe, G., J. B. Hirsh \& A. K. Anderson. 2007. Positive affect increases the breadth of attentional selection. Proceedings of the National Academy of Sciences of the United States of America 104. 383-388.

Rubin, D. L. (1992). Nonlanguage factors affecting undergraduates' judgments of nonnative English-speaking teaching assistants. Research in Higher Education, 33, 511-531. 
Rubin, D. L. (2002). Help! My professor (or doctor or boss) doesn't talk English! In J. Martin, T. Nakayama, \& L. Flores (Eds.), Readings in intercultural communication: Experiences and contexts (pp. 127-137). Boston, MA: McGraw Hill.

Rubin, D. L. (2012). The power of prejudice in accent perception: reverse linguistic stereotyping and its impact on listener judgments and decisions. In J. Levis \& K. Levelle (Eds.), Social factors in pronunciation acquisition: Proceedings of the 3rd Pronunciation in Second Language Learning and Teaching Conference (pp.11-18). Ames, IA: Iowa State University.

Sánchez-Hernández, A. (2018). A mixed-methods study of the impact of sociocultural adaptation on the development of pragmatic production. System, 75, 93-105.

Saville-Troike, M. (2017). Introducing second language acquisition (2 ${ }^{\text {nd }}$ ed.). Cambridge, UK: Cambridge University Press.

Sheen, Y. (2006). Exploring the relationship between characteristics of recasts and learner uptake. Language Teaching Research, 10, 361-392.

Sheen, Y. (2008). Recasts, language anxiety, modified output, and L2 learning. Language Learning, 58, 835-874.

Stein, N. L., \& Glenn, C. G. (1979). An analysis of story comprehension in elementary school children. In R. Freedle (Ed.), New directions in discursive processing (pp. 53-120). Norwood, NJ: Ablex.

Swain, M. (2013). The inseparability of cognition and emotion in second language learning. Language Teaching, 46, 195-207.

Taylor Reid, K., P. Trofimovich \& M. O’Brien. 2018. Social attitudes and speech ratings: Effects of positive and negative bias on multiage listeners' judgments of second language speech. Studies in Second Language Acquisition. Published online 13 November 2018. 
https://doi.org/10.1017/S0272263118000244

Toohey, K. (2000). Learning English at school: Identity, social relations, and classroom practice. Bristol, UK: Multilingual Matters.

Trofimovich, P., A. Ammar \& E. Gatbonton. 2007. How effective are recasts? The role of attention, memory, and analytical ability. In A. Mackey (ed.), Conversational interaction in second language acquisition: A series of empirical studies, 171-195. Oxford: Oxford University Press.

Vedder, P., \& Virta, E. (2005). Language, ethnic identity, and the adaptation of Turkish immigrant youth in the Netherlands and Sweden. International Journal of Intercultural Relations, 29, 317-337.

Vissers, C. T. W. M., Virgillito, D., Fitzgerald, D. A., Speckens, A. E. M., Tendolkar, I., Van Oostrom, I., \& Chwilla, D. J. (2010). The influence of mood on the processing of syntactic anomalies: Evidence from P600. Neuropsychologia, 48, 3521-3531.

Watts, D. J. (1999). Small worlds: The dynamics of networks between order and randomness. Princeton, NJ: Princeton University Press.

Yilmaz, Y., \& Granena, G. (2016). The role of cognitive aptitudes for explicit language learning in the relative effects of explicit and implicit feedback. Bilingualism: Language and Cognition, 19, 147-161.

Yoshida, R. (2010). How do teachers and learners perceive corrective feedback in the Japanese language classroom? The Modern Language Journal, 94, 293-314. 